\title{
Regulación de uso del suelo urbano: discusión sobre el caso de Curitiba*
}

\section{Urban land use regulation: discussion about the Curitiba's case}

\author{
Rosa MOURA**
}

Ya el urbanismo ha sido entendido como una serie de cosas que van desde la provisión de servicios de agua, alcantarillado y electricidad para los pocos conjuntos habitacionales edificados, hasta la promulgación de leyes capaces de asegurar la efectiva polución de las nacientes que abastecen de agua las ciudades. También se ha entendido por urbanismo la imposición de posturas municipales destinadas a segregar las funciones urbanas y el espacio, con más énfasis que aquella imposta por las disparidades de ingreso. Se incluyen ahi otras posturas destinadas a dificultar la edificación de toda y cualquier construcción y a engordar toda la mafia que se inicia con los fiscales municipales y si extiende hasta los gabinetes de los alcaldes, pasando por las administraciones regionales y cámaras municipales.

Cherkezian; Bolaffi, 1998, p. 126

\section{RESUMO}

O processo de construção e aprovação do novo conjunto de leis relativas ao zoneamento de uso e ocupação do solo em Curitiba oferece elementos para uma análise dos conflitos de interesses que regem a constituição de um arcabouço legal e da luta simbólica que traduz na elaboração de um discurso que não se realiza nos termos da lei, mas que se cristaliza no imaginário dos citadinos. Tentando analisar esse processo e identificar dispositivos passíveis de serem generalizados como eficazes no controle de ocupação e uso do solo de outras cidades-modelo, na busca do protagonismo nos movimentos de inserção na reestruturação econômica internacional, este texto examina e sumariza observações quanto: ao apoio da lei no reforço à modelização urbana de Curitiba; à ausência de mecanismos e instrumentos que

\footnotetext{
* Texto producido para el workshop "Law and Urban Space", promovido por el International Research Group on Law and Urban Space (IRGLUS), Cairo, junio, 2000 .

** Geográfa, atuando en el "Instituto Paranaense de Desenvolvimento Econômico e Social" (Ipardes), profesora colaboradora del curso de especializacíon "Técnicas em Análise Ambiental", del Departamento de Geografia da Universidade Federal do Paraná (UFPR), y participante del proyecto de extensión "Espaços de Mediações de Conflitos Fundiários: Implicações Jurídicas, Sociais e Ambientais”, de la Pró-Reitoria de Extensão e Cultura da UFPR.
} 
contemplem suas relações com o espaço metropolitano; aos efeitos socioambientais decorrentes da aplicação da lei; às questões referentes à constitucionalidade e à observação de princípios democráticos; às disposições referentes à ampliação da atratividade ao capital internacional; a sua abertura à participação da sociedade civil e à legitimidade de seus resultados.

Palavras-chave: legislação urbana, zoneamento de uso e ocupação do solo, gestão metropolitana

\begin{abstract}
In 1999, a new land use law was approved in Curitiba. Its construction and approval process offers elements to discuss the meaning of a legal frame in the reinforcement of a hegemonic power around a metropolitan space, and the creation of conditions to attract the international capital, mainly from the real estate market. Trying to analyse this process, identifying elements possible to be generalised in the land use regulation of protagonists' cities, this study examines and summarises observations on the topics: law for highlight the city-model; the lack of metropolitan instruments; conflicts between Instruments and particular interests; urban and social effects; constitutionality and observation of democratic principles. Finalising, the study intends to discuss that the dispositions included in the law and its illegitimate participation procedures have resulted in a refusing among society segments.
\end{abstract}

Key-words: urban legislation, land use regulation, metropolitan management

La reciente aprobación de un conjunto de leyes que van a regular el espacio de Curitiba ha provocado gran polémica en la ciudad. Ese conjunto es compuesto por siete leyes que disponen cuanto al zoneamento de uso y ocupación del suelo, instrumentos de la política urbana, transferencia de potencial constructivo, incentivos a los programas de habitación de interés social, anillo sanitarioambiental, unidades de conservación y código forestal.

Desde 1997, la cámara de vereadores ${ }^{1}$ de la municipalidad ha puesto en discusión la necesidad de elaboración de un nuevo plan director para Curitiba, en virtud del defasaje del plan vigente - aprobado en 1966 y implementado desde los años 70 - con el desarrollo vivido por la ciudad en los últimos 30 años. Con la promoción de un seminario ${ }^{2}$ ampliamente se analizó el plan en uso y los cambios urbanos, concluyendo con unanimidad por la necesidad de un plan que tomase en cuenta el espacio metropolitano y no solamente el área limitada en el perímetro político-territorial de Curitiba (GAZETA, 1997; FÓRUM, 1997). Para cumplir la conclusión, ha sido recomendado un proceso participativo para la construcción del nuevo plan, lo que empezaría a ocurrir inmediatamente, bajo la coordinación del Instituto de Pesquisa y Planificación Urbana de Curitiba (IPPUC).

Pasados dos años, en agosto de 1999, el alcalde ha presentado oficialmente a los vereadores de la municipalidad un proyecto de ley para alteración del zoneamento de la ciudad y otras providencias. Con críticas apenas de la bancada de la oposición, ese proyecto ha sido mal recibido tanto por el movimiento popular cuanto por representantes de entidades profesionales o del empresariado.

Por el hecho de la perplejidad social, la cámara llamó un segundo seminario y, en dos días (4 y 5 de noviembre),

1 En la estructura de los poderes en Brasil, la legislación de peculiar interés de los municipios es una competencia de los “vereadores" - representantes del pueblo, electos por votación directa.

2 Seminario "Plano Diretor de Curitiba: uma abordagem metropolitana", realizado en siete sesiones temáticas, una a cada semana, entre los días 15 de mayo y 27 de junio de 1997. En el debate público abierto por el seminario, han compuesto las mesas regularmente representantes del poder público, de entidades no gubernamentales involucradas con el movimiento popular o ambientalista - conforme la temática del día -, del empresariado local, de la universidad y técnicos de renombre que hayan participado en la elaboración del plan. 
discutió públicamente la propuesta. El seminario concluyó que el proyecto presentado no se configuraba en un nuevo plan director y que esa era la necesidad básica para la organización de un espacio que se había metropolizado. Solicitaba rediscutir el proceso, exigiendo mayor participación de las fuerzas sociales representadas.

No obstante esas conclusiones, solicitaciones y posicionamientos formales contrarios, el alcalde de Curitiba hizo el protocolo oficial del proyecto en la cámara de vereadores en 12 de noviembre.

En medio a protestos, las leyes fueron aprobadas en régimen de urgencia, sin la apreciación de las comisiones temáticas de la cámara, en diciembre de 1999; en 3 de enero de 2000, fueron sancionadas por el alcalde y entrarom en vigor en 4 de abril siguiente.

Intentando analizar ese proceso y buscando identificar los elementos posibles para la generalización de los modelos de regulación del uso y ocupación urbana en el ámbito del protagonismo de las ciudades, el refuerzo del poder hegemónico en el espacio metropolitano y la creación de condiciones para el ejercicio de atractividad a los capitales internacionales, particularmente el capital inmobiliario, este relato examina y sintetiza observaciones cuanto a: a) ausencia de instrumentos de alcance metropolitano; b) los instrumentos creados y juegos de intereses; c) efectos sociales y ambientales de la nueva ley; d) cuestiones de la constitucionalidad y la observación de los principios democráticos; e) participación corporativa y figurativa de la sociedad; y f) la ley como elemento de realce del modelo Curitiba.

\section{La ausencia de instrumentos de alcance metro- politano}

El primer punto polémico de las leyes es que no contemplan el espacio metropolitano, ni siquiera ofrecen mecanismos que incentiven la gestión articulada. Eso es una ausencia injustificable pues reproduce una de las mayores limitaciones del plan anterior.

Desde 1960 hasta 1996, la población de Curitiba ha crecido de aproximadamente 360 mil habitantes para 1.476.253. Tal crecimiento, además de haber agregado miles de metros cuadrados en el área urbana ocupada de la ciudad, ha adentrado el territorio de las municipalidades vecinas, constituyendo un espacio urbanizado en el cual viven 2,4 millones de habitantes, en condiciones sociales de gran desigualdad.
En ese periodo, no apenas el incremento de la población ha cambiado las características de la ciudad sino el peso de su participación en la economía del Estado, con creciente integración en esa dinámica de las demás municipalidades del área metropolitana. En 1975, la participación de la Región Metropolitana de Curitiba (RMC) en el agregado económico del Paraná ha sido $13,47 \%$; en 1996 , representava más que $60 \%$ del valor agregado de la industria en el Estado y 39,8\% del valor agregado total. Esa participación ocurre de forma concentrada, principalmente en el polo metropolitano, seguido por Araucária y São José dos Pinhais, limítrofes a él.

El dinamismo de esa base productiva altera de modos cualitativo y cuantitativo la apariencia del polo metropolitano, provocando la densificación de usos y ocupación, y la modernización de las funciones urbanas. Grandes equipos comerciales, culturales, de servicios públicos, condominios residenciales, así como infraestructuras han logrado la recualificación del diseño urbano. Los ejes estructurales que han inducido una ocupación linear en Curitiba, mismo consolidados como marcos físicoterritoriales de la historia de su urbanismo, actualmente empiezan a dividir la orientación de la ocupación con vectores transversales, que crean nuevas centralidades internas y externas a la municipalidad.

Una ocupación selectiva ocurre en el espacio metropolitano, condicionada por el valor de la tierra y de la habitación, el precio de las mejorías urbanas resultantes de las intervenciones urbanísticas y el control asociado a la planificación, reservando para Curitiba aquellos moradores de superiores ingresos. La legislación más flexible de los municipios vecinos, la oferta de tierras por la iniciativa privada - muchas veces en áreas de captación hídrica parceladas antes de la ley federal 6.766, que impide tal ocupación - y el sistema de transporte colectivo que sustenta la ligación con el polo han tornado viable, a los más pobres, la ocupación de sus áreas fronterizas (ULTRAMARI; MOURA, 1994).

Tal desigualdad tiende a agravarse debido a refuncionalización de algunas áreas del espacio metropolitano para adecuación a los padrones de competitividad y atractividad a las actividades modernas.

Actualmente las clases de rendimientos medio a alto están optando por las mismas áreas vecinas, atraídas por la oferta de condominios de lujo, perfectamente conectados a Curitiba. En las periferias se ubican aún los nuevos distritos industriales, como el de São José dos Pinhais, 
entre otros, que conforman el polo automotor del Estado. Buscan también las ubicaciones en municipios de la periferia, grandes emprendimientos comerciales, empresariales, y tantos otros de largo porte. No obstante, las municipalidades menos dinámicas continuarán excluidas del proceso, abrigando la segregación de la pobreza y de actividades secundarias.

Ese escenario justifica la elaboración de un nuevo plan director para la ciudad, con una concepción que se vuelva a la inserción de Curitiba en un conjunto más amplio de municipios, integrados espacial, funcional, económica, social y ambientalmente. Un plan director que sea elaborado en conjunto con la totalidad de municipios que constituyen el espacio continuo de la metrópoli.

Mismo con la evidente necesidad de planificación y gestión regional integrados, la base legal e institucional de gestión de ese aglomerado permanece fraccionada, como confirma el conjunto de leyes recientemente aprobado. Él no presenta dispositivos que vengan a garantizar una intervención integrada entre el polo y los demás municipios metropolitanos, tampoco ofrece posibilidades de que haya una compatibilización legislativa y programática futura.

La percepción del primordial que es concebir un plan integrado a la metrópoli está presente en el discurso oficial. Desde el mensaje que encaminó las leyes al legislativo o en el material que fue divulgado vía Internet, hasta las posiciones expresas en la midia, la Región Metropolitana es una preocupación omnipresente.

En la Internet, en la home page de la municipalidad, el texto que presenta las leyes se abre afirmando: "No es más posible pensar Curitiba aislada de los municipios vecinos y las intervenciones deben ser realizadas dentro de la perspectiva metropolitana" (PREFEITURA MUNICIPAL DE CURITIBA, 1999a). En los objetivos del mensaje que introduce la ley de zoneamento se incluye "promover la planificación integrada a las políticas de desarrollo de los municipios que componen la región metropolitana”. (PREFEITURA MUNICIPAL DE CURITIBA, 1999b) La prensa refuerza ese discurso, llamando atención en titulares como "Expansión de la RM motiva nueva ley" (GAZETA DO POVO, 4 abr. 2000), entre otros.

Pero, en el cuerpo de las leyes hay pocas referencias a tan segura percepción y tan contundente retórica. Estas ocurren en dos momentos: el primer, en la ley de zoneamento, cuyos objetivos apuntan "el incentivo a la ocupación ordenada a lo largo de los ejes de ligación con demás municipios de la Región Metropolitana de Curitiba"; el segundo, en la ley de transferencia de potencial constructivo, cuyo Artículo 3. dispone que

Será admitida la transferencia de potencial constructivo mediante convenios o consorcios entre Curitiba y los demás municipios que componen la RMC, de forma a asegurar las condiciones ambientales adecuadas a la protección y preservación de las nacientes.

Aparentemente integrador por asumir que la ocupación y el uso del suelo metropolitano obedecen una continuidad funcional y físico-territorial, no logra fijar los parámetros para su realización, que van a ser definidos en negociaciones ajenas al proceso legislativo, y consecuentemente se van escapar a un control abierto, por parte de la sociedad.

La principal característica de la ley de zoneamento aprobada es la creación de ejes de densificación, exactamente en los corredores metropolitanos. Las disposiciones refuerzan el papel local de esos ejes cuanto a los usos y ocupación, cuando el propio mensaje que lo introduce constata su función como sistemas integradores regionales, lo que exige disciplinas específicas para funciones más apropiadas a tales tipos de corredores.

Otros sectores especiales propuestos podrían cumplir un rol metropolitano más integrador, como en el caso del sector institucional, de habitación de interés social, de las áreas verdes o del anillo de conservación sanitario ambiental.

La ley no establece tampoco cualquier tipo de mecanismo de regulación a la presión por ocupación y usos que vengan a ocurrir en el área ora en refuncionalización, o en las áreas pobres periféricas a Curitiba, legales o ilegales. Situaciones que implican en complejos problemas sociopolíticos y que exigen una conjunción regional de instrumentos de control.

Ella no creó caminos adecuados a la participación en la gestión, incluyendo los gobiernos municipales, las demás instancias de gobierno y los agentes actuantes en el espacio metropolitano. También no ofrece posibilidades de articulación de una acción regional para las funciones públicas de interés común a más de una municipalidad, o mecanismos tributarios compensatorios, lo que puede hacer con que sea acentuada la segregación socioespacial ahora existente. 
Se comprueba que, por más que en el discurso la RMC haya sido incorporada como espacio de planificación conjunta, en la ley permanece el trato peculiar al interés del municipio, presente en los varios fragmentos existentes en la ley anterior. La disculpa oficial se apega en los límites de competencia y autonomía municipal. Pero, si no hay como legislar sobre otras municipalidades, nada excluye la posibilidad de ofrecer mecanismos de acción articulada, tampoco justifica la omisión de un debate regional en el proceso.

De esa forma, el contenido de las leyes es conservador, postergando activar nacionalmente el debate cuanto a la importancia de se repensar la competencia de gestión de estos espacios aglomerados que se multiplican en todo el territorio brasileño.

\section{Instrumentos creados y juegos de intereses}

La ley que trata de los instrumentos de la política urbana concentrase en dos instrumentos que se consubstancian en el "suelo creado" y en la "transferencia de potencial constructivo", relegando mecanismos verdaderamente capaces de promover mejorías sociales. Como que ignorando las constituciones federal y estadual, esos instrumentos no hacen alteraciones substanciales ni democratizan la producción del espacio urbano, pues no introducen la posibilidad del cumplimiento de la función social de la propiedad, en acuerdo con las leyes fundamentales. Por fin, hacen un aumento del potencial de construcción en ejes de elevada circulación, sin la contraprestación por parte de los beneficiados (GAIO, 2000).

Fueran privilegiados los instrumentos que permiten la creación de parques públicos o la preservación del patrimonio histórico, por el cambio del potencial constructivo, más, según el Sindicato de la Industria de la Construcción Civil (Sinduscon), el alto costo del suelo creado - lo correspondiente a $75 \%$ del valor del $\mathrm{m}^{2}$ adicionado - "estaría perjudicando la eficiencia de la medida, pues no incentiva propietarios de inmuebles a su uso" (MARTINS, 1999a). Además, los cambios de potencial inducen a una significativa especulación en el valor del suelo, lo que transforma la tierra en Curitiba en algo todavía más selectivo.

Ocurre aún una ausencia de compromiso del propietario en el ámbito de los incentivos propuestos, en la medida en que no hay disposiciones sobre las responsabilidades de los beneficiados, los plazos y las sanciones aplicables para las hipótesis de su descumplimiento, así como hay efectiva ausencia de control por parte de la administración pública.

Además de los términos genéricos, restrictos a principios conceptuales, trámites operacionales y responsabilidades organizativas, la reglamentación carece de mejor definición de su contenido y de los mecanismos de su utilización, materias que fueran transferidas para el Poder Ejecutivo Municipal. ${ }^{3}$ La flexibilidad de la ley abrió amplias posibilidades de creación de otros instrumentos, por medio de decretos, sin la participación de los canales democráticos de producción jurídica, reservando el control tecnocrático y centralizado de la gestión urbana, con un descompromiso entre las propuestas y la ordenación legal consistente y coherente de la política urbana municipal (MINISTÉRIO PÚBLICO DO PARANÁ, 1999).

Entre las concesiones están, por ejemplo, la modificación de los parámetros de uso y ocupación del suelo de ciertos sectores de la ciudad, la definición de áreas públicas de recreación y la reformulación o institución de nuevos instrumentos de política urbana.

Una disposición que merece consideración a parte es la elevación del coeficiente de uso de terrenos para altura/ $6(\mathrm{H} / 6)$ en los ejes existentes o recién creados, con la imposición de mayor alejamiento de los límites del lote. Su introducción está apoyada en la búsqueda del rescate de la calidad ambiental, perdida en la urbanización concentrada.

Con esa regulación, la ley ha conquistado la crítica unánime de los representantes del sector inmobiliario. ${ }^{4}$ En realidad, ellos afirman que tal exigencia sólo es compatible de ser obedecida por grandes inversores, dado que más que $90 \%$ de los constructores sindicalizados son pequeños y no tendrían como competir dentro de los parámetros impuestos. A los capitalistas locales, no les disponen aportes de recursos para tal, lo que abre la perspectiva de atracción

3 En el día siguiente a la entrada en vigor de las leyes, 16 dispositivos ya estaban reglamentados (DOLCI, 2000).

4 Han rechazado públicamente el H/6, el Sinduscon, la Asociación de Dirigentes de Vendas del Mercado Inmobiliario, el Consejo Regional de Correctores Inmobiliarios, el Instituto de Ingeniería del Paraná y la Asociación Paranaense de Oficinas de Arquitectura. Cf. SINDUSCON acusa IPPVC de favorecer as contrutoras. GAZETA DO POVO, Curitiba, 3 abr. 2000, p. 3. 
de inversores internacionales, en reproducción de lo que ocurre en otras partes (CREA-PR, 2000).

Además, los nuevos ejes de densificación propuestos representan una perfecta posibilidad de configuración de una centralidad moderna y atractiva en la ciudad, respectando exigencias del mercado inmobiliario externo. Y eso es lo que teme el mercado inmobiliario local, cuyos integrantes, por cierto, estarán excluidos del proceso (VALENTE, 2000).

Instrumentos de carácter más redistributivo, dispuestos en la Constitución Federal, podrían ser incorporados en la ley, como el impuesto sobre la propiedad territorial y predial urbana progresivo en el tiempo, incidiendo sobre las áreas sin edificación, objetos de especulación inmobiliaria; la desapropiación de inmuebles urbanos, y la contribución de mejoría en resultado de obras públicas, pero se quedaron olvidados (MINISTÉRIO PÚBLICO DO PARANÁ, 1999).

\section{Efectos socioambientales}

Las consecuencias de los nuevos ejes con el aumento en la densidad, la transformación del perfil formal de la ciudad, y los cambios demográficos e institucionales de tales vectores metropolitanos seguramente van a afectar la capacidad de la infraestructura urbana, la calidad de vida una tarjeta postal de Curitiba -, y la distribución de la población y actividades. Se espera que van provocar la degradación de áreas centrales, relocar y intensificar los movimientos hacia la periferia, en municipalidades vecinas, principalmente de los moradores de bajo rendimiento, en una asociación a futuros proyectos de gentrification.

Mientras la ley anterior ha permitido la construcción de una "muralla de concreto" a lo largo de los ejes estructurales, los efectos de los nuevos ejes aprobados serán más problemáticos, ya que están orientados en la dirección de las áreas de las nacientes del valle del Rio Iguaçu. Ellos permiten una integración de 62 millones de $\mathrm{m}^{2}$ construidos en la malla urbana de Curitiba, mismo restando 80 millones disponibles en los ejes ya existentes. La transferencia del potencial constructivo puede agregar más 120 millones, lo que "representa la posibilidad de solamente en el municipio de Curitiba se acomodaren entre 6 millones de habitantes, en una estimativa conservadora, a 11 millones, en una estimativa optimista" (FRAGOMENI, 2000).

Las nuevas áreas de densificación irán también competir con el centro de la ciudad en la localización de actividades comerciales y de servicios, reduciendo el potencial de revitalización central.

La planificación local y su recorte físico-territorial ya están cerca de los límites, y pueden sucumbir apenas con pequeñas incorporaciones y cambios de usos y coeficientes. En principio eficiente, hoy, produce efectos contrarios, sea por las deseconomias de una densificación impropia, sea por la saturación de la capacidad de las infraestructuras y servicios. Desde luego, esa configuración necesita cambios profundos. Contrariamente, lo que se ha introducido en el conjunto de leyes, con la posibilidad de la inducción de nuevas densificaciones, seguramente va a agudizar esas deseconomias (CREA-PR, 2000; AVALIAÇÃO, 1999).

En el ámbito ambiental, las leyes específicas sustituyen por la noción de "bosques nativos" y "bosques nativos relevantes" la de "bosques de preservación permanente", infringiendo el Código Forestal (Ley Federal n. ${ }^{\circ}$ 4771/65) y descaracterizando la existencia de estos bosques por él protegidos.

Bajo esa noción, el beneficio fiscal concedido a los propietarios de las áreas con unidades de conservación ambiental acaba por no cumplir su objetivo, visto que el incentivo puede vigorar por varios años y ser suspenso posteriormente por una autorización para corte, después del crecimiento de los árboles y su valorización para abate. Eso significa una alteración legislativa inconstitucional y perjudicial al medio ambiente y a los presupuestos públicos (MINISTÉRIO PÚBLICO DO PARANÁ, 1999).

\section{Constitucionalidad y observación de los principios democráticos}

Los aspectos ambientales llaman atención a la inconstitucionalidad en las disposiciones: no pueden los municipios editar leyes locales de uso y ocupación del suelo que establezcan normas menos rígidas que las establecidas por leyes federales, bajo la alegación de que se legisla sobre asuntos de interés local. La competencia para legislar sobre el medio ambiente es apenas de la Unión, Estados y Distrito Federal. A los municipios cabe apenas suplir la legislación federal y estadual.

A más del medio ambiente, el modo con que el proceso ha sido conducido muestra que no hubo cualquier respeto a los requisitos constitucionales que exigen la existencia de "plan directores" a las ciudades con población superior a 20 miles de habitantes. El conjunto de leyes de- 
sarticuladas ignora la necesidad real de repensar la planificación y la sistemática de gestión, actualmente en uso en la ciudad.

Conforme el Artículo 182, § $1^{\circ}$, de la Constitución Federal, el plan director, aprobado por la Cámara Municipal, "es el instrumento básico de la política de desarrollo y de expansión urbana”. La Ley Orgánica del Municipio de Curitiba determina en el Artículo 149, que el zoneamento urbano es parte obligatoria del plan director.

Se concluye que el primer instrumento a ser instituido debería ser el propio plan director, con el objetivo de orientar el proceso global de producción, apropiación y uso del espacio urbano, de modo ordenado y construido a través de un pacto negociado con los ciudadanos, considerando, inclusive, los diversos aspectos estructuradores de la región metropolitana. Como instrumento básico de desarrollo urbano, el plan director debería objetivar el ordenamiento de las funciones sociales de la ciudad y garantizar el bienestar de sus habitantes, así como determinar el contenido de la propiedad urbana, en la medida en que establecería la forma con que la misma cumple su función social - disposiciones textuales de la Constitución Federal, incorporadas por la Estadual y la Ley Orgánica del Municipio de Curitiba. que será

Explícitamente, esa Ley, en el Artículo 155, prescribe

Creado un Consejo Municipal de Planificación, formado por representantes de distintas entidades de la sociedad civil, que tomarán parte en la elaboración y ejecución del Plan Director del Municipio. [Establece, además, en el Artículo 212], que los consejos municipales de que trata esta Ley Orgánica deberán ser reglamentados en el plazo de ciento y ochenta días de su promulgación.

El consejo de Planificación jamás ha sido creado.

Con base en ese conjunto articulado de dispositivos, concluyese que la elaboración de la ley de zoneamento y de las demás, sin que tomen parte de un nuevo plan director, ha afrontado visiblemente los dispositivos constitucionales. Y más, pues las leyes en análisis ignoran el principio consagrado en la Constitución Federal, de que la política urbana sea realizada en una distribución equilibrada de competencias entre los poderes ejecutivo y legislativo del municipio, por atribuyeren a los órganos gestores y de planificación la competencia para administrar, reglamentar o alterar la reglamentación pré-establecida sobre las más diversas actividades, sin que sea necesario informar o consultar a la cámara municipal.

La Constitución Federal refuerza la autonomía del municipio lo concibiendo como un ente en la estructura del Estado brasileño, ampliando su competencia legislativa de interés local y su competencia de ejecución de la política urbana. A la vez, atribuye a los estados la articulación de mecanismos de gestión regional que contemplen la unidad del espacio urbano trascendente a los límites político-administrativos de municipios y esferas de competencias. Eso provoca una relativa ambigüedad en la concretización de las disposiciones legales.

En la ausencia de una racionalidad cuanto a enfrentar el anacronismo espacio/territorio, el cumplimento parcial de la ley puede provocar ilegitimidad en la intervención. O sea, mismo el plan director como un instrumento que se apoya en una estructura legal particular a los intereses del municipio, cuando incidente en una aglomeración urbana, puede transformarse en un mecanismo segmentario y fomentar la desigualdad, si se reporta apenas a una parte del espacio con ocupación y usos en continuidad.

Apenas una planificación que definiera las prioridades de intervención regional, planteando eliminar las contradicciones socioeconómicas de ese espacio, lograría evitar la canalización de inversiones públicas a los intereses corporativos, lo que priva la atención a los intereses de la colectividad.

\section{La participación corporativa y figurativa}

En el ámbito de los instrumentos, la ley olvida los mecanismos participativos, confirmando el modo de actuación del gobierno de la ciudad, en el cual la participación de los ciudadanos fue restricta a aceptar las intervenciones urbanas tecnocraticamente planificadas, implementadas y impuestas en un proceso top-down.

Desde su construcción y aprobación, las leyes han sufrido la imposición de intereses segmentados. Han estado en la mesa de discusión solamente aquellos representantes del capital, básicamente el inmobiliario, excluyendo la participación de la sociedad civil organizada y restringiendo los trabajos en el legislativo municipal a un curto tiempo para la apreciación y votación del proyecto -no más que 25 días, sin cumplir los trámites del regimiento, como la apreciación por las comisiones de la Cámara, y en pleno 
inicio del receso parlamentar. Eso ejemplifica un proceso donde han prevalecido las negociaciones por intereses particulares al revés de deseos y demandas colectivas.

En el principio, las clases empresariales fueran las únicas consultadas y las únicas que discutieron las enmiendas al proyecto. Cuando concluido por el IPPUC, se vehiculó por Internet ${ }^{5}$ y desencadenó una secuencia de exposiciones "performáticas" en las administraciones regionales de la ciudad, conducidas por el alcalde, incomprensibles para la mayoría de los moradores, desinformados sobre el asunto y con expectativas bastante particularizadas. A los segmentos organizados, pocas presentaciones han ocurrido, la principal movilizada por la cámara de vereadores, pero sin tiempo suficiente para que se realizara un análisis previo del contenido de las propuestas, lo que permitiría la evaluación de sus implicaciones en la vida de la ciudad. Peor, sin que las conclusiones o recomendaciones de estas hayan sido consideradas por el IPPUC.

En la Universidad Pública se iniciaron simulaciones de densificación y sus impactos negativos en el ambiente urbano, fue discutida la agresión de sus disposiciones a la Constitución Federal y otras leyes mayores, y fue apuntada la inadecuación a las necesidades de gestión metropolitana del espacio, así como se enfatizaron sus problemas ambientales (MINISTÉRIO PÚBLICO DO PARANÁ, 1999; AVALIAÇÃO, 1999; NIMAD, 1999). La sociedad organizada ha resaltado la falta de debates y la ausencia total de mecanismos para participación, en el cuerpo de las leyes propuestas (Relatório, 1999a). Apenas el sector ligado al capital inmobiliario ha logrado algún respeto, y sus sugestiones han sido incorporadas.

Inmediatamente después de la divulgación de la propuesta de las leyes por el ejecutivo municipal, el Sinduscon, con la afirmación de que las entidades no habían sido llamadas, ha hecho la amenaza de ir a la justicia en el caso del texto ser aprobado sin modificaciones (MARTINS, 1999a). El sindicato recordaba el ciclo de debates solicitado en 1998 y la creación de un "consejo de la ciudad."

En reunión sigilosa con apenas diez entidades lideradas por el Sinduscon, el alcalde de Curitiba reconsideró y admitió la adición de enmiendas en los proyectos de ley. ${ }^{7}$
La reunión y sus resultados provocaron malestar en la cámara de vereadores y en la sociedad, y cambió profundamente la posición de las entidades del capital inmobiliario en la conclusión del proceso.

En el inicio esas entidades estivieron junto a los demás sectores oponentes, ya que las leyes introducieron limitaciones a sus prácticas. Al final, después de acuerdos que incluyeran la dilatación de los plazos de vigencia de los dispositivos en uso y su participación en los trámites de la reglamentación necesaria, en cambio de apoyo al alcalde en las próximas elecciones, garantizaron su silencio (MARTINS, 1999b).

Actualmente, sustentan que "hubo participación efectiva de la sociedad organizada" (IEP, 2000) o que la participación "fue plena y que toda la sociedad fue llamada a contribuir, rechazando la posibilidad" (VALENTE, 2000).

Las entidades académicas y el movimiento popular, alijados de cualquier discusión, alegan que el ejecutivo municipal no permitió debates efectivos, pero se legitimaó, con el apoyo de la midia, demostrando, una vez más, su habilidad en conducir por sí solo los destinos de la ciudad. En carta abierta a la población solicitarom que las leyes aprobadas no fueran sancionadas y propusieron la abertura de un amplio proceso de discusión, sugerindo que

Una acción articulada entre la Coordenação da Região Metropolitana de Curitiba (Comec), IPPUC, municipios metropolitanos, iniciativa privada y sectores organizados de la sociedad civil, producirá, instituyendo un padrón democrático de toma de decisiones, un plan director capaz de poner Curitiba y región a la altura de sus ciudadanos (FÓRUM, 1999b).

Ese proceso recoloca la sistemática de la participación pasiva de la comunidad, con énfasis en la "ingeniería del consenso" y en la eficacia de un discurso que crea la ilusión de que hay participación ciudadana en las decisiones del Poder Público (SÁNCHEZ, 1993).

Con una demostración de fuerza, no solamente sobre la sociedad, pero incluso sobre el poder local de los municipios periféricos, este capítulo legislativo reitera todavía el significado de que el universalismo de la Ley es

5 El site dispone en la Internet (http.//www.curitiba.pr.gov.br) los proyectos de ley y los mapas correspondientes, pero con acceso restricto ya que requiere Corel Draw 5 y 8 para abertura, y impresión colorida apenas en tamaño $90 / 150 \mathrm{~cm}$, en driver ploter $\mathrm{HP}-750$ - requisitos estos prácticamente profesionales.

6 Oficio enviado al ejecutivo, con las signaturas del Sinduscon, Federación de las Industrias del Paraná, Instituto de Ingeniería del Paraná y Asociación Paranaense de Oficinas de Arquitectura, solicitando no apenas el consejo y más debate - hasta obtener el consenso -, sino la ejecución del plan director metropolitano.

7 Entre las enmiendas del acuerdo estaba incluida la institución del Consejo de Urbanismo, pero no fue concretizada, tampoco reclamada por ese segmento. 
un mecanismo poderoso en el ejercicio de dominación simbólica como "imposición de la legitimidad de un orden social, aumentando los efectos de la autoridad social que la cultura legitima y sus detentores ya ejercen para dar toda su eficacia práctica a la coerción jurídica" (BOURDIEU, 1989, p. 246).

\section{La ley como elemento de realce del modelo de Curitiba}

El plan director de Curitiba es considerado un "ícone" del modelo a que se convertió la ciudad. Pero, es fácil observar que su eficiencia está perdida en el pasado.

Su papel en la modelización de Curitiba se dió en la consolidación del proceso de planificación en los años 70, favorecido por el contexto político nacional de la década. Con suporte institucional, recursos nacionales e internacionales y pactos con el capital local, se firmó un patrón de relaciones entre los gestores y los propietarios de los medios de producción que garantizaron el éxito de la experiencia (OLIVEIRA, 1995). Además, ocurrió una continuación administrativa en su implementación, con Jaime Lerner, personalizando el proceso. Son curtos los intervalos en los cuales fuerzas de grupos políticos opositores administraron la ciudad, lo que dificultó cambios sustanciales en el proyecto (SÁNCHEZ, 1993).

La acomodación de los intereses dominantes al rededor de una propuesta política materializada técnicamente permitió la consolidación de ese proyecto particularmente hegemónico y garantizado las condiciones internas de sustentación del modelo.

El gran referencial del plan fue el sistema de circulación y transporte colectivo, siempre con innovaciones en los detalles, como el ómnibus articulado, el bi-articulado, sus plataformas móviles para embarque y desembarque, la puerta en lado invertido, como en el caso del "ligeirinho" (línea directa), la identificación visual en colores fuertes y las "estaciones-tubo".

La nueva ley garantizó la recolocación del urbanismo en la orden del día y la renovación del transporte de masa, prevista con la construcción de un modal elevado para tránsito de un monorail en uno de los futuros ejes de densificación, renovando el premiado sistema en operación.

Completa el reciclage del modelo de Curitiba, la refuncionalización de su área metropolitana, con la amplia producción de infraestructuras, y la actualización de los instrumentos legales, con el objetivo de exponer una imagen moderna, competitiva en este contexto global, y atractiva a los grupos de mejor rendimiento, así como a los potenciales agentes de inversión.

La creación de nuevos ejes de densificación en los vectores de ligación a los distritos industriales o a gran equipamientos en el área metropolitana, como el aeropuerto, y la introducción del aumento en el coeficiente de construcción, exigiendo lotes más largos que van desplegar la implementación de proyectos más complejos, son acciones puntuales que realzan el modelo de ciudad local e internacionalmente. No obstante, siguen excluyentes.

Seguramente, la condición de modelo podría romper el virtualismo de las imágenes y consustanciarse en una práctica incluyente, a partir de la construcción de una propuesta apropiada para transformar la planificación local en metropolitana, adecuando su estructura legal y los mecanismos para una gestión regionalmente articulada.

Para reconquista y democratización de la calidad de vida sería prioridad vincular la refuncionalización de la RMC a una agenda social, diseñando un proyecto económico de adecuación del espacio a las exigencias de las relaciones internacionales sin descartar atención a las áreas socialmente segregadas o ambientalmente vulnerables, superando las desigualdades y garantizando un futuro sostenible.

Todas esas acciones sólo hacen sentido si realizadas de una forma democrática, con amplia participación de las organizaciones de la sociedad, como dispone la estructura de las leyes fundamentales y como exige el compromiso con el derecho de la ciudadanía. En contrario, la ironía de los autores del epígrafe de este trabajo estaría traduciendo una cruel realidad también para Curitiba y RMC. 


\section{REFERENCIAS}

AVALIAÇÃO do plano de zoneamento e uso do solo de Curitiba. Curitiba: Departamento de Arquitetura da UFPR, 1999 (texto preliminar).

BOURDIEU, P. O poder simbólico. [S. 1.]: Bertrand Brasil, 1989.

CHERKEZIAN, H.; BOLAFFI, G. Os caminhos do malestar social: habitação e urbanismo no Brasil. Novos Estudos Cebrap, mar. 1998.

CREA-PR. Zona de atritos. Revista Crea-PR, Curitiba, ano 3, n. 8, jan./fev., 2000.

DOLCI, L. A. Lei proíbe paredões de edifícios. Gazeta do Povo, Curitiba, 5 abr. 2000.

FÓRUM em Defesa da Cidade. Carta aberta ao Sr. Cassio Taniguchi, Prefeito de Curitiba. Curitiba, 15 dez. 1999b. 11/1999a. em Defesa da Cidade. Relatório da reunião de 25/

FÓRUM Habitat Paraná. Visão do Fórum Habitat Paraná ao Seminário Plano Diretor de Curitiba: uma Abordagem Metropolitana. FHPR, Curitiba, set., 1997, 16 p.

FRAGOMENI, L. H. A Curitiba desenhada pela nova lei. In: A LEI DE ZONEAMENTO DE CURITIBA EM DEBATE, 2000, Curitiba. Anais... Curitiba: Fundação Pedroso Horta, 2000.

GAIO, D. Análise dos instrumentos urbanísticos propostos pela lei. In: A LEI DE ZONEAMENTO DE CURITIBA EM DEBATE, 2000, Curitiba. Anais... Curitiba: Fundação Pedroso Horta, 2000.

IEP. Já em vigor nova lei de zoneamento. Mensageiro, ano 28, n. 545, p. 1, abr., 2000.

INTEGRAÇÃO com a Região Metropolitana é considerada fundamental para o novo plano. Gazeta do Povo, Curitiba, 6 jun. 1997.

INTEGRAÇÃO é a saída para a RM de Curitiba. Gazeta do Povo, Curitiba, 20 jun. 1997.

MARTINS, R. Polêmica não convence Ippuc a rediscutir lei de zoneamento. Gazeta do Povo, Curitiba, 22 nov. 1999a.
Prefeitura volta atrás e admite mudanças na lei de zoneamento. Gazeta do Povo, Curitiba, 24 nov. 1999b.

MINISTÉRIO PÚBLICO DO PARANÁ. Projeto de extensão universitária. Espaços de Mediação de Conflitos Fundiários: implicações jurídicas, sociais e ambientais. Análise das propostas de alteração da legislação de zoneamento de Curitiba. Curitiba: Pró-Reitoria de Extensão da UFPR/PUC-PR, 1999.

O FUTURO de Curitiba na dependência da RM. Gazeta do Povo, Curitiba, 8 jun. 1997.

OLIVEIRA, D. A política do planejamento urbano: o caso de Curitiba. Campinas. 1995. Tese (Doutorado em Ciências Sociais) - Universidade Estadual de Campinas.

PREFEITURA MUNICIPAL DE CURITIBA. Projeto de Lei de Zoneamento, Uso e Ocupação do Município de Curitiba de 12 novembro de 1999. Mensagem n. 32 do Prefeito Municipal ao Presidente da Câmara de Vereadores de Curitiba. Curitiba, 12 nov. 1999.

Proposta de zoneamento e uso do solo. Disponible em: <http://www.curitiba.pr.gov.br>.

SÁNCHEZ, F. Curitiba imagem e mito: reflexão acerca da construção social de uma imagem hegemônica. Rio de Janeiro, 1993. Disertación (Mestrado) - Instituto de Pesquisa e Planejamento Urbano e Regional, Universidade Federal do Rio de Janeiro.

SEMINÁRIO SOBRE O USO DO SOLO E DOS RIOS NA CURITIBA DO NOVO MILÊNIO, 1999, Curitiba. Anais... Curitiba: Núcleo Interdisciplinar de Meio Ambiente e Desenvolvimento da UFPR. 1999.

SINDUSCON acusa IPPUC de favorecer as construtoras. Gazeta do Povo, Curitiba, 3 abr. 2000. p. 3.

ULTRAMARI, C.; MOURA, R. Metrópole Grande Curitiba: teoria e prática. Curitiba: Ipardes, 1994.

VALENTE, R. O posicionamento da classe empresarial. In: A LEI DE ZONEAMENTO DE CURITIBA EM DEBATE, Curitiba, 2000. Anais... Curitiba: Fundação Pedroso Horta, 2000. 